\title{
Sepse por Serratia marcescens KPC
}

\section{Serratia marcescens KPC sepsis}

\section{unitermos}

Klebsiella pneumoniae carbapenemase (KPC)

Carbapenemase

Serratia

Infecção de corrente sanguínea

\section{resumo}

A resistência aos carbapenems entre as bactérias não fermentadoras de glicose é comumente descrita. Porém, os relatos de resistência aos carbapenems em enterobactérias ainda são fatos isolados. Neste relato de caso, descrevemos um caso de infecção generalizada por Serratia marcescens carreadora de gene blaKPC. No Brasil, já foram relatados casos de isolados de Klebsiella pneumoniae e Escherichia coli carreando gene blaKPC, ficando evidente a emergência desse tipo de carbapenemase e sua disseminação entre espécies diferentes de enterobactérias em nosso país.

\section{abstract}

Carbapenem resistance among Gram-negative non fermentative bacteria is widely known, whereas carbapenem resistance among Enterobacteriaceae is rare. In this study we describe a case of sepsis caused by Serratia marcescens carrying blaKPC gene. In Brazil, cases of KPC have been reported in Klebsiella pneumoniae and Escherichia coli, which shows the emergence of this kind of carbapenemase and its dissemination among different species of Enterobacteriaceae in our country. key words

Klebsiella pneumoniae carbapenemase (KPC)

Carbapenemase

Serratia

Bloodstream infection 
Paciente do sexo feminino, 74 anos, com histórico de cardiopatia, deu entrada em uma unidade de emergência do Sistema Único de Saúde (SUS) com descrição de malestar generalizado. Após algumas horas de internação, a paciente evoluiu com parada cardiorrespiratória, que foi revertida. No dia seguinte à internação, foi transferida para uma unidade de terapia intensiva (UTI) de outro hospital do SUS, localizado em outro município. Ao longo da internação na UTI, a paciente evoluiu com sintomatologia de sepse urinária. Iniciou-se terapia empírica com antibióticos de amplo espectro e foi necessário o auxílio de ventilação mecânica para o quadro de insuficiência respiratória. Foram colhidas três amostras de hemoculturas antes do início da terapia antimicrobiana e a paciente evoluiu para o óbito. As hemoculturas positivaram após seis horas de incubação em equipamento automatizado (Bactec). A coloração de Gram das hemoculturas revelou bastonetes Gram-negativos e, após 24 horas de incubação em meios de ágar sangue e chocolate, as colônias foram direcionadas para identificação e teste de sensibilidade automatizados em equipamento Microscan Walkaway (Siemens).

O resultado da identificação fenotípica foi confirmado por reação de polimerização em cadeia (PCR). No teste de sensibilidade aos antimicrobianos, foram testados penicilinas, cefalosporinas, monobactam, aminoglicosídeos, quinolonas e carbapenems. Os resultados de resistência aos carbapenems (meropenem e imipenem) foram confirmados por meio de metodologia de gradiente de concentração com obtenção de concentração inibitória mínima real (Etest). Foi realizado teste de Hodge modificado para a detecção fenotípica para a produção de carbapenemase. Tendo em vista a necessidade para fins epidemiológicos e terapêuticos, realizamos a pesquisa genotípica dos principais genes que expressam carbapenemases e que podem ser disseminados por plasmídeos (SPM, VIM, IMP, OXA-23 e KPC) e avaliamos a sensibilidade à tigeciclina.

O isolado foi identificado como Serratia marcescens e revelou resistência aos antibióticos amicacina, ampicilina tazobactam, aztreonam, cefazolina, cefepime, cefotaxima, cefotetan, ceftazidime, ceftriaxona, cefuroxime, ciprofloxacin, ertapenem, gentamicina, imipenem, levofloxacina, meropenem, piperacilina tazobactam, tobramicina e sulfatrimetoprim-metoxazol. Os resultados das concentrações inibitórias mínimas, realizadas por metodologia Etest, para imipenem e meropenem foram $>32 \mu \mathrm{g} / \mathrm{ml}$. O resultado da concentração inibitória mínima para tigeciclina, realizada por metodologia Etest, foi de $\leq 2 \mu \mathrm{g} / \mathrm{ml}$. Embora sendo a única opção terapêutica, não há indicação formal para seu uso em infecção de corrente sanguínea. Os resultados das genotipagens por PCR real time para os genes produtores de carbapenemases de classes A, B e D: blaSPM, blaVIM, blalMP e blaOXA-23 foram negativos. O resultado da genotipagem por PCR real time para o gene blaKPC foi positivo e, posteriormente, será discriminado dentro dos subtipos (1-4). O teste para detecção de carbapenemase (Hodge modificado segundo o Clinical and Laboratory Standards Institute [CLSI]) revelou resultado positivo.

A classe dos carbapenems é considerada de grande utilidade no tratamento de infecções por bactérias multirresistentes, principalmente aquelas que associam múltiplos mecanismos de resistência enzimática (hiperprodução de betalactamase produzida por enterobactérias que hidrolizam antibióticos betalactâmicos [AmpC] e betalactamase de espectro estendido [ESBL]). A resistência aos carbapenems entre as bactérias não fermentadoras de glicose é comumente descrita na nossa realidade atual. Porém, a resistência aos carbapenems em enterobactérias ainda é fato isolado(1), que normalmente está relacionado com outros mecanismos de resistência, como alterações de porinas ou produção de efluxo ativo, ou, ainda, carbapenemases mediadas por outros genes ou associaçõoes destes ${ }^{(2)}$. A descrição de enterobactérias carreadoras do gene blaKPC foi inicialmente descrita em Klebsiella pneumoniae e, posteriormente, em algumas outras espécies isoladas em vários países no mundo ${ }^{(3)}$. Por ser um gene localizado em um plasmídeo móvel, pode ser facilmente transferido entre bactérias da mesma espécie ou entre espécies diferentes ${ }^{(3)}$. Neste relato de caso, descrevemos um quadro de infecção generalizada por Serratia marcescens ${ }^{(4)}$, carreadora de gene blaKPC. Como no Brasil já temos descritos casos de isolados de Klebsiella pneumoniae e Escherichia coli carreando gene blaKPC, fica evidente a emergência desse tipo de carbapenemase e sua disseminação por espécies diferentes de enterobactérias em nosso país ${ }^{(1,4)}$. Uma das principais dificuldades em lidar com bactérias portadoras de KPC é que, em determinados casos, não há resistência plena aos carbapenems e, com isso, a detecção desse gene se torna obrigatória para assegurar o sucesso terapêutico, especialmente em situações de resultados possivelmente demonstrando falsa sensibilidade. 


\section{Referências}

1. MOLAND, E. S. et al. Plasmid-mediated, carbapenemhydrolysing $\beta$-lactamase, KPC-2, in Klebsiella pneumoniae isolates. J Antimicrob Chemother, v. 51, n. 3, p. 711-4, 2003.

2. VILLEGAS, M. et al.; COLOMBIAN NOSOCOMIAL RESISTANCE STUDY GROUP. First detection of the plasmid-mediated class A carbapenemase KPC-2 in clinical isolates of Klebsiella pneumoniae from South America. Antimicrob Agents Chemother, v. 50, n. 8, p. 2880-2, 2006.
3. VILLEGAS, M. V. et al.; COLOMBIAN NOSOCOMIAL RESISTANCE STUDY GROUP. First identification of Pseudomonas aeruginosa isolates producing a KPCtype carbapenem-hydrolyzing $\beta$-lactamase. Antimicrob Agents Chemother, v. 51, n. 4, p. 1553-5, 2007.

4. ZHANG, R. et al. Plasmid-mediated carbapenemhydrolysing $\beta$-lactamase KPC-2 in carbapenemresistant Serratia marcescens isolates from Hangzhou, China. J Antimicrob Chemother, v. 59, n. 3, p. 574-6, 2007. 